\title{
MAXIMAL OXYGEN UPTAKE AND RELATED FUNCTIONS IN MALE AND FEMALE ATHLETES.
}

\author{
R. WATSON, M.Sc., Dip. P.E., and KATHLEEN DEVENNEY \\ Physiology Department, Chelsea College of Physical Education, Eastbourne, Sussex.
}

\section{Introduction}

Exercise and work physiologists agree that the evaluation of maximum oxygen intake capacity is essential in the objective evaluation of an individual's capacity to perform aerobic work. This index is related to cardiovascular-respiratory capacity and for years has been accepted as a criterion for the assessment of physical fitness, ie. cardiovascular fitness. However, even with the great amount of research done in the area of applied physiology, the research is still typically experimental in nature and results are often contradictory. This is partially due to the relatively small number of subjects tested, and the differences and difficulties in experimental technique. Nevertheless, it is agreed that a substantial relationship between endurance capacity and maximum oxygen uptake exists which is independent of the form in which the maximum oxygen uptake is reported. In most investigations, subjects have been highly trained endurance male athletes, and maximum oxygen uptake has been correlated with other anthropometric and cardio-respiratory parameters including body weight, cardiac output, haemoglobin content, heart rate and pulmonary ventilation etc.

The present study was designed to obtain values for maximum oxygen consumption in both male and female trained athletes during strenuous exercise on the bicycle ergometer, and to determine any existing relationships between maximum oxygen consumption and pulmonary ventilation, heart rate and work capacity.

\section{Material}

The nine male subjects included six English, two Welsh, and one Kenyan, all of whom were in training for either national or international competition.

The eight female subjects included seven English and one Welsh athletes. Three of the subjects were in training for international athletics competitions, one was in training for international field hockey competition and the other four were advanced physical education students in good physical condition.

The current study had several limitations. Firstly, the sample was very small, and very selective. Secondly, due to a lack of medical training by the experimenters, blood samples could not be drawn from subjects to measure blood lactate levels. Therefore, the only criteria used to determine if maximum oxygen consumption had been attained was the plateauing off of consumption and failure for that value to be increased with further increased work load. For similar reasons, cardiac output was not measured, so that the only index of cardiovascular function was heart rate.

\section{Method}

Each subject was tested individually using an open circuit technique and a Müller bicycle ergometer. When the subject reported to the laboratory he was first familiarized with the experimental procedures. Dracard disposable electrodes were then attached to the subject on three body loci to monitor the heart beat:

(1) top of sternum

(2) 6 th rib, mid-clavicular line

(3) 8 th rib, mid-axillary line

These electrodes were then plugged into a multi channel pen recorder.

The subject was then familiarized with the bicycle and pacemaker control. The height of the saddle was adjusted to each individual for comfort and so that there was a slight bending of the knee when the front part of the foot was placed on the pedal in its lowest position. With the subject seated on the bicycle, a British Oxygen Company anatomically malleable rubber face mask was fitted to his facial contours covering the mouth and nose, thus allowing normal breathing. The facemask was held in place using a Connell head harness. To this was attached a modified Otis-McKerrow low resistance translucent breathing valve. This three way high velocity valve permitted unrestricted inspiration and exhalation. The weight of the valve was supported by a steel spring suspended from an independent support structure.

The subject was then given a 5 minute warm up on the bicycle to familiarize him to the pedal rate (maintained at 90 revolutions per minute for the males, $75 \mathrm{rpm}$ for the females), and the breathing apparatus. During this time, oxygen percentage in the air, Wet and Dry bulb temperatures, barometric pressure and ambient temperature were measured for S.T.P.D. standardization.

For those experiments performed as steady state work loads, the exercise session started at 60 watts, increasing by 40 watts for each new work load. Each work load was performed for 5 minutes followed by a 2 minute recovery. During recovery the subject remained 
seated on the bicycle. Work finished when the athlete could not maintain the required pedalling frequency, as indicated by the pacemaker control.

For those athletes working on an increasing work load, following the warm up period, the bicycle was set at 60 watts and automatically increased in work load with time.

Expired air was collected during exercise via lightweight polyurethene tubing, into three different $150 \mathrm{ml}$. Plysu Douglas Bags. Controlling valves were used so that the expired air flow could easily be diverted from one bag to another during the collection of minute samples. Each collection of minute ventilation was measured for oxygen composition using a Beckman E-2 oxygen analyzer and/or a Servomex paramagnetic analyzer. Minute volumes were then measured using a KofranyiMichaelis Respirometer, and values corrected to standard temperature and pressure, dry (S.T.P.D.) Oxygen consumption was then calculated in the manner described previously.

The heart rate was monitored throughout the exercise and continuously recorded by the polygraph. Three heart rates for each minute were calculated by measuring the time required for eleven peaks of the QRS waves as recorded (10 beats). It was found that if a smaller Douglas-Rudolph breathing valve was used, significantly lower ventilation values were obtained. The authors also found that although the Dracard disposable electrodes, as opposed to rigid cup silver electrodes, were more convenient to use, profuse sweating by the male subjects d uring strenuous exercise caused electrochemical artifacts that severely hampered electrocardiographic recordings.

In the steady state, the rate at which oxygen passes into the blood stream is the difference between the rates of oxygen inspiration and expiration. The relation may be stated:

$$
\dot{v}_{02}=\dot{\mathbf{v}}_{\mathrm{IO}_{2}} \cdot \dot{\mathrm{V}}_{\mathrm{EO}_{2}}
$$

where $\dot{\mathrm{V}}_{\mathrm{IO}_{2}}$ is the rate per unit time at which $\mathrm{O}_{2}$ is inspired at standard temperature and pressure, dry (S.T.P.D.) $\dot{\mathrm{V}}_{\mathrm{EO}}$ is the rate per unit time at which $\mathrm{O}_{2}$ is
expired at S.T.P.D.

$\dot{\mathrm{V}}_{02}$ is the rate per unit time at which the oxygen crosses the pulmonary membrane ( $0_{2}$ consumption) S.T.P.D.
$\dot{\mathrm{V}}_{10}$ can be determined from the inspiratory flow rate and the fraction of oxygen in the inspired gas $\left(\mathrm{F}_{10} \%\right)$ thus:

$$
\dot{\mathrm{V}}_{\mathrm{IO}_{2}}=\dot{\mathrm{V}}_{\mathrm{I}} \times \mathrm{F}_{\mathrm{IO}_{2}} \%
$$

similarly:

$$
\dot{\mathrm{V}}_{\mathrm{EO}_{2}}=\dot{\mathrm{V}}_{\mathrm{E}} \times \mathrm{FEO}_{2} \%
$$

the original equation then becomes:

$$
\dot{\mathrm{V}}_{\mathrm{I}} \times \mathrm{F}_{\mathrm{I}_{2}}=\dot{\mathrm{V}}_{\mathrm{E}} \times \mathrm{FEO}_{2}=\dot{\mathrm{V}}_{\mathrm{O}_{2}}
$$

The values $\dot{V}_{I}$ and $\dot{V}_{E}$ are nearly identical and are equal to the minute ventilation of the lung. This can be easily measured. $\mathrm{F}_{10} \%$ may also be determined by simple analysis of inspired air (in this case room air), as can FE0\%. The difference of these two measures yields the fraction of utilized oxygen $\left(\mathrm{FUO}_{2} \%\right.$ ). The equation may now be simplified:

$\dot{\mathrm{V}}_{\mathrm{E}} 1 / \mathrm{min} \times \mathrm{FU}_{2} \%=\dot{\mathrm{V}}_{0_{2}} 1 / \mathrm{min}$

(all gases standardized to S.T.P.D.)

Oxygen consumption was calculated from these two parameters throughout the present investigation.

Although data is contradictory about the maximum oxygen uptake during various types of work in various positions, Asstrand and Saltin (1961) (5) found that combined arm and leg work in the sitting or supine position reveals the same values for maximum oxygen uptake, heart rate and stroke volumes as work in the sitting position with only the leg muscles. This does not however take into account claims that running on a treadmill, as opposed to riding a bicycle ergometer, will produce a higher maximum oxygen uptake. Hermansen, and Saltin (1969) (21) in comparing the bicycle at 50 rpm to a treadmill running uphill at 30 found that the running produced $0.281 \mathrm{1} / \mathrm{min}$, (7\%) higher oxygen uptake, although no significant difference in maximum values for work capacity, pulmonary ventilation and heart rate were reported. This is probably due to the slightly larger total muscle mass involved in running.

Testing standards and techniques are wide and varied depending upon the researcher and available equipment. Because a bicycle ergometer was used in this study, the technique used was similar to that described by Åstrand (1952) (2) and Watson (1970) (36) with some modifications.

\section{Results}

The mean data of maximum values for all individual male and female subjects is presented in tables 1 and 2 
Table 1. Male subjects:

Individual Maximum values of Physiological Response to Exercise.

\begin{tabular}{|c|c|c|c|c|c|c|c|}
\hline \multirow[t]{2}{*}{ Subject } & $\begin{array}{l}\text { Body } \\
\text { Wt. }\end{array}$ & Max.* & $\underset{\operatorname{Vax}_{\mathrm{E}}}{\mathrm{Max}^{*}}$ & $\begin{array}{l}\text { Max.* } \\
\text { Fu02 }\end{array}$ & $\begin{array}{l}\text { Max. } \\
\dot{\mathrm{V}}_{02}\end{array}$ & $\operatorname{Max}^{*}{ }^{*}$ & $\begin{array}{l}\text { Max.* Parameter } \\
\text { fHThat Levelled }\end{array}$ \\
\hline & kgs. & $\begin{array}{l}\text { Load } \\
\text { watts }\end{array}$ & $\begin{array}{l}\text { 1/min. } \\
\text { S.T.P.D. }\end{array}$ & $\%$ & $\begin{array}{l}\text { 1/min. } \\
\text { S.T.P.D. }\end{array}$ & $\mathrm{ml} / \mathrm{min} / \mathrm{kg}$ & $\begin{array}{cc}\text { Beats/ } & \text { Off First } \\
\text { min. } & \left(\dot{\mathrm{V}}_{02} \text { or } \mathrm{f}_{\mathrm{H}}\right)\end{array}$ \\
\hline
\end{tabular}

Group 1.

Steady state work load:

\begin{tabular}{|c|c|c|c|c|c|c|c|c|}
\hline M. B. & 75.4 & 300 & 123. & 3.6 & 4.43 & 58.7 & 200.0 & $\mathrm{fH}^{\mathrm{H}}$ \\
\hline C. C. & 79.5 & 340 & 99. & 5.1 . & 5.06 & 66.1 & 171.4 & $\mathrm{fH}$ \\
\hline K. K. & 64.5 & 300 & 115. & 3.8 & 4.78 & 73.1 & 181.8 & $\mathrm{f}^{\mathrm{H}}$ \\
\hline A. $\mathrm{H}$. & 67.2 & 340 & 107. & 4.2 & 4.49 & 66.8 & 176.4 & $\begin{array}{c}\text { Max. } V_{02} \text { first } \\
\text { Max. } \mathrm{fH}=181.8\end{array}$ \\
\hline R. McA. & 60.9 & 260 & 66. & 5.0 & 3.30 & 54.2 & 157.8 & $\begin{array}{c}\text { Max. } \dot{V}_{02} \text { first } \\
\text { Max. } \mathrm{fH}=176.4\end{array}$ \\
\hline F.S. & 70.9 & 340 & 131. & 3.3 & 4.72 & 66.5 & 162.1 & $\mathrm{fH}^{\mathrm{H}}$ \\
\hline G. S. & 67.0 & 340 & 98. & 3.6 & 3.53 & 52.6 & 162.1 & $\mathrm{fH}^{\mathrm{H}}$ \\
\hline MEAN & & & 108 & 4.0 & 4.32 & 62.5 & 172.9 & \\
\hline S. D. & & & \pm 18.2 & \pm .7 & \pm .61 & \pm 6.9 & \pm 13.9 & \\
\hline
\end{tabular}

Group 2.

Increasing work load:

\begin{tabular}{|c|c|c|c|c|c|c|c|}
\hline D. C. & 59.5 & 403 & 94. & 3.3 & 3.10 & 52.1 & 181.8 \\
\hline B. $\mathrm{H}$. & 70.0 & 450 & 127. & 3.4 & 4.32 & 61.6 & 182.8 \\
\hline MEAN & & & 110.5 & 3.35 & 3.71 & 56.8 & 182.3 \\
\hline MEAN & & & 109 & 3.8 & 4.18 & 61.3 & 175.2 \\
\hline S. D. & & & \pm 18.2 & \pm .99 & \pm .62 & \pm 6.94 & \pm 13.4 \\
\hline
\end{tabular}

for all male

subjects

*all maximum values are those that correspond with the measurement of maximum $\dot{V}_{02}$.

respectively. Maximum values represent those measures that correspond to maximum oxygen consumption. All the male arhletes achieved at least 300 watts of work, the highest individual work load being 380 watts during steady state work, and 450 watts during increasing work load. All the female subjects achieved at least 220 watts during steady work and at least 170 watts during increasing work load. The highest individual value was 300 watts.

Pulmonary ventilation for the male subjects showed the typical relationship of increased ventilation with increased work loads. The better trained females of group 1 showed similar responses, whereas the lesser trained females of group 2 showed generally more erratic responses. The greatest ventilation volume achieved by a male runner was 127 litres/min S.T.P.D. and by a female was 88.5 litres/min.

The percentage of oxygen extraction in all cases increased to a maximum point and then began to decline well before the onset of exhaustion. The percentage fraction of oxygen utilised by those doing steady state work (both males and females) was higher than those performing increasing work loads. A maximum of $5.3 \mathrm{ml}$ $02 / 100 \mathrm{ml}$ of inspired air was utilised by one male subject and $5.2 \mathrm{ml} 0_{2} / 100 \mathrm{ml}$ by one female subject, although the mean $\mathrm{FUO}_{2} \%$ taken at maximum oxygen consumption was only $3.8 \%$ for both groups. 
Table 2. Female subjects:

Individual Maximum values of Physiological Response to Exercise.

$\begin{array}{llc}\text { Subject } & \text { Max.* } & \text { Max.* } \\ & \text { Work } & \dot{V}_{\mathrm{E}} \\ & \text { Load } & \text { 1/min. } \\ & \text { watts } & \text { S.T.P.D. }\end{array}$<smiles></smiles>

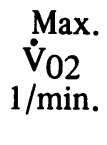

Max.*
fH
beats/
min.

Max.

$\mathrm{fH}$

Achieved

beats/min.

Parameter

Off First

$\left(\dot{\mathrm{V}}_{02}\right.$ or $\left.\mathrm{fH}\right)$

Group 1.

Steady state work load:

$\begin{array}{lcccccc}\text { B. B. } & 220 & 88.5 & 3.7 & 3.26 & 181.4 & 181.4 \\ \text { S. M. } & 350 & 70.0 & 5.0 & 3.50 & 181.8 & 181.8 \\ \text { P. Y. } & 220 & 76.0 & 3.6 & 2.74 & 187.8 & 187.8 \\ \text { MEAN } & & 78.3 & 4.2 & 3.13 & 183.6 & 183.6 \\ \text { S. D. } & & \pm 7.6 & \pm .66 & \pm .32 & \pm 2.8 & \pm 2.8\end{array}$

\section{Group 2.}

Increasing work load:

$\begin{array}{llllllll}\text { M. G. } & 170 & 72.0 & 3.0 & 2.16 & 176.0 & 181.8 & \text { Max. } \dot{V}_{02} \text { first } \\ \text { M. E. } & 190 & 70.0 & 3.5 & 2.66 & 193.0 & 200.0 & \text { Max. V02 first } \\ \text { S. E. } & 210 & 60.0 & 3.4 & 2.04 & 162.0 & 162.0 & \text { fH } \\ \text { C. D. } & 190 & 59.0 & 4.2 & 2.48 & 181.8 & 181.8 & \text { fH } \\ \text { L. L. } & 150 & 47.0 & 4.5 & 2.11 & 200.0 & 207.0 & \text { Max. V02 first } \\ \text { MEAN } & & 61.6 & 3.7 & 2.49 & 182.6 & 186.5 & \\ \text { S. D. } & & \pm 10.0 & \pm .54 & \pm .32 & \pm 13.1 & & \end{array}$

\section{MEAN}

67.8

3.8

2.51

183.0

$\mathrm{fH}$

fH

$\mathrm{fH}^{\mathrm{H}}$

S. D.

for all female

$\pm 11.7$

$\pm .72$

$\pm 2.8$

185.4

subjects

*all maximum values are those that correspond with the measurement of maximum $\dot{V}_{02}$.

The heart rates in both male and female subjects indicated the expected linearity with increased work loads up to maximum and then levelled off so that no increase in work contracted a higher heart rate. In all but two of the trained males and three of the lesser trained females, maximum heart rate was achieved prior to maximum oxygen consumption. The mean maximum heart rates recorded during the last minute of exercise were 177.2 and 185.4 beats $/ \mathrm{min}$. males and females respectively. These are very similar to the mean values presented in tables 1 and 2 which represented mean heart rates recorded during the period of maximum oxygen uptake. The highest individual $\mathrm{fH}$ recorded for a male subject was 200 beats/min., and for a female 207 beats/min., the lowest maximum of 162 beats $/ \mathrm{min}$. being obtained by two males and one female.

Oxygen consumption followed the usual pattern of increasing linearity with work up through submaximal work loads but levelled off at approximately $85 \%$ maximum work capacity. This levelling off was most evident in the female subjects who achieved greater than 250 watts work and those male subjects who achieved greater than 300 watts of work.

The greatest value for oxygen consumption was by $\mathrm{C}$. C. with $5.06 \mathrm{1} / \mathrm{min}$., but when adjusted to body weight was only $66.1 \mathrm{ml} / \mathrm{min} / \mathrm{kg}$, so that $\mathrm{K}$. $\mathrm{K}$. with a maximum $\hat{\mathrm{V}}_{0_{2}}$ of $73.1 \mathrm{ml} / \mathrm{min} / \mathrm{kg}$ actually achieved the highest value.

The highest $\dot{\mathrm{V}}_{02}$ attained by a female was $\mathrm{S}$. M. with $3.5 \mathrm{1} / \mathrm{min}$. Mean maximum $\hat{\mathrm{V}}_{0}$ for males was 4.18 $1 / \mathrm{min}$., or $61.3 \mathrm{ml} / \mathrm{min} / \mathrm{kg}$; and $2.511 / \mathrm{min}$. for females. In all subjects except one ( $R$. McA.), maximum $\mathrm{V}_{0_{2}}$ was recorded during the last, or within the last 3 minutes of exercise before complete exhaustion. 
Means and standard deviations for both groups at each work load are indicated on tables 3 and 4 for the

Table 3. Male subjects: $\mathbf{N}=9$

Means and Standard Deviations of $\mathrm{fH}, \dot{\mathrm{V}}_{02}$ and $\dot{\mathrm{V}}_{\mathrm{E}}$.

Work

watts

$\mathrm{fH}$ beats/min.

Mean S. D.

$\begin{array}{rrr}50 & 97.0 & \pm 6.6 \\ 100 & 106.8 & \pm 8.4 \\ 150 & 123.7 & \pm 14.7 \\ 200 & 139.3 & \pm 13.4 \\ 250 & 164.8 & \pm 12.4 \\ 300 & 172.2 & \pm 12.8 \\ 350 & 171.5 & \pm 5.8\end{array}$

Table 4. Female subjects: $N=8$

Means and Standard Deviations of $\mathrm{fH}, \dot{\mathbf{V}}_{02}$ and $\dot{\mathbf{V}}_{\mathbf{E}}$.

\begin{tabular}{rlr} 
Work & \multicolumn{2}{l}{$\mathrm{fH}^{\mathrm{H} \text { beats/min. }}$. } \\
watts & Mean & S. D. \\
& & \\
50 & 118.3 & \pm 9.2 \\
100 & 135.7 & \pm 8.2 \\
150 & 165.0 & \pm 13.1 \\
200 & 179.3 & \pm 13.5 \\
250 & 181.0 & \pm 4.5
\end{tabular}

For the male athletes, mean heart rates increased in a straight line $(r=.99)$ with oxygen consumption up to the point $\dot{\mathrm{V}}_{\mathrm{O}_{2}}=4.0 \mathrm{1} / \mathrm{min}$. and $\mathrm{fH}=172.0$ beats $/ \mathrm{min}$. (See figure 1).

The females showed a similar relationship with the mean $\mathrm{fH}$ increasing up to $\dot{\mathrm{V}}_{\mathrm{O}_{2}}=2.241 / \mathrm{min}$., $(\mathrm{r}=.86)$, and plateauing off to 181 . beats/min. (See figure II).

Tables 3 and 4 showed that:

In all instances, for a given $\dot{\mathrm{V}}_{2}$ level or work load, females had a higher $\mathrm{f} H$ than the male athletes. At every work load, the male athlete elicited a higher oxygen consumption than the female athlete. parameters of heart rate, pulmonary ventilation and oxygen consumption.

Figures 1 and 2 show that:

Mean pulmonary ventilation for the subjects started out increasing in a linear relationship with oxygen consumption but assumed a curvilinear relationship before exhaustion. $\dot{V}$ E continued to increase while $\dot{V}_{0_{2}}$ levelled out.

\section{Discussion}

Determination of maximum oxygen consumption is certainly not a new idea in exercise physiology as related work has been going on for years. A. V. Hill and $H$. Lupton (1923) (24) laid the basis for evaluating relationships between aerobic and anaerobic metabolism in muscle and established that there was an inter-individual 

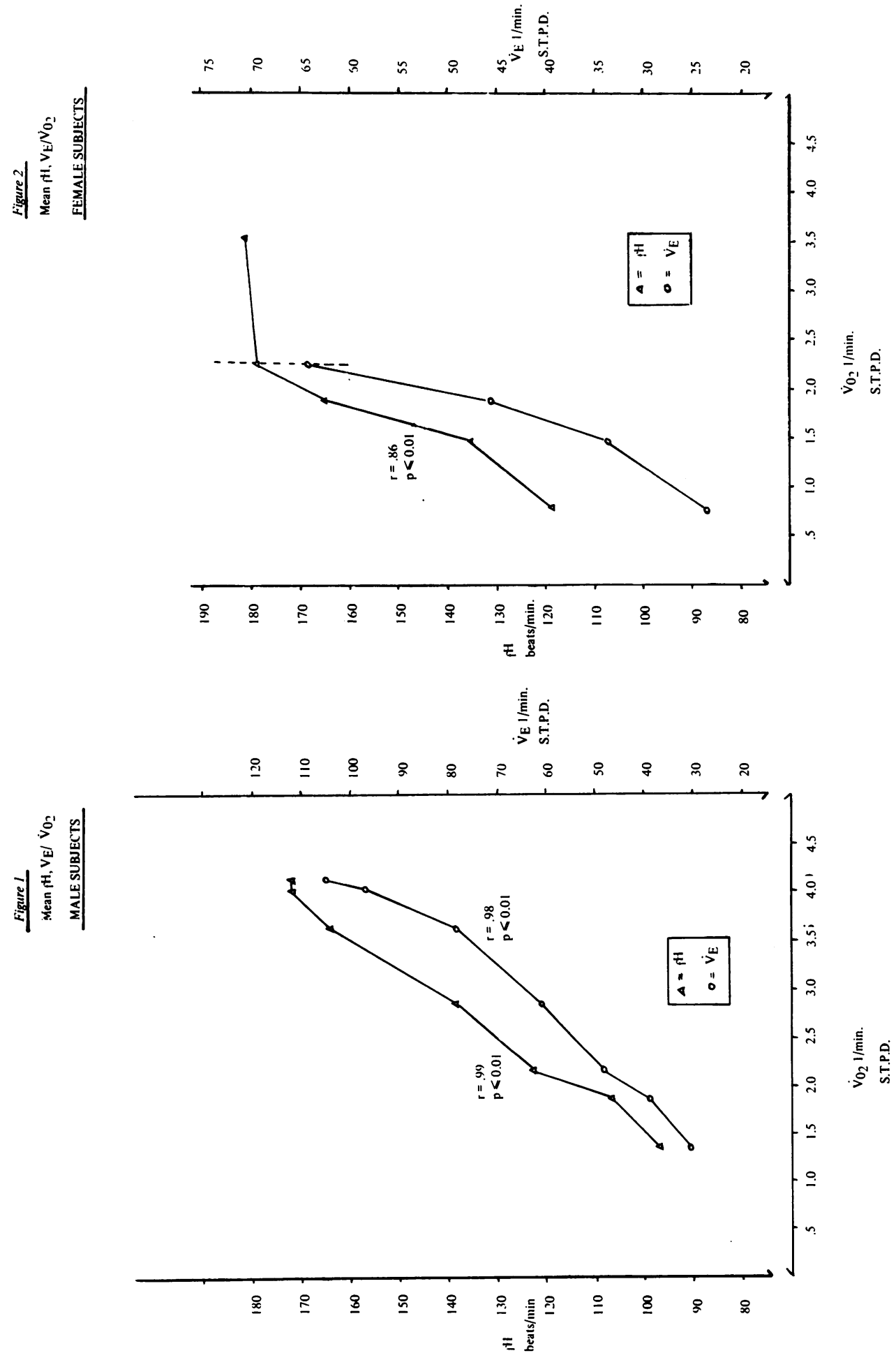

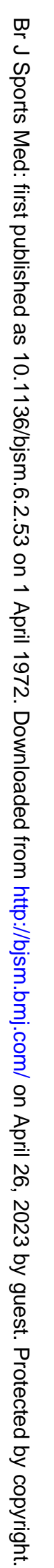


variation in maximum oxygen uptake which was crucial for the ability to perform prolonged muscular work, Herbst (1928) (19) first demonstrated that oxygen consumption increases with an increase in running speed (i.e. an increase in work), up to a certain maximum level and then levelled off. D. B. Dill (1933) (12) reported a linear regression between oxygen uptake and heart rate. Subsequent studies have added more to the knowledge of oxygen utilization, oxygen debt and the relationship between these and physical work capacity: Dill, Edwards, Margaria (1933) (13); and Dill, Talbott, Edwards (1932) (14).

Technical aspects of measuring oxygen uptake as well as its implications, have been studied by Taylor, Buskirk and Henschel (1955) (35) and Rowell, Taylor and Wang (1964) (33) and Åstrand (1952) (2).

Oxygen uptake and related functions have also been subjects of investigations by Michael and Horvath of the U.S., (1965) (29), Ikai of Japan (1966) (25), Wilmore of the U.S., (1969) (38) and others. Cotes, Davies, Healy (1967) (10), in England have investigated aerobic work capacity of healthy British males and females; and Hamley and Sen have assessed human performances and tolerance to heavy work (1968) (17).

More recently, Watson (1970) (36), using English female physical education students on the bicycle ergometer measured and used maximum oxygen consumption as an index of aerobic work capacity. Relationships between maximum oxygen uptake and age and sex have been studied in male and female Japenese adolescents by Matsui and Miyashita (1971) (28). It was found that the males had significantly higher oxygen capacities with increases in age.

Maximum oxygen consumption has been used widely as a parameter for comparing various international athletes and predicting performances: Maksud et al (1970) (27) using male and female Olympic skaters; Magel et al (1967) (26) using swimmers; Carter et al (1966) (8) using Peter Snell; and Åstrand and Saltin (1967) (6) using athletes.

A. V. Hill (1926) (23) has defined maximum oxygen consumption as the level reached when "the oxygen intake per unit time has attained its maximum and remains constant... owing to the limits of the circulatory and respiratory systems." In normal subjects the maximum oxygen consumption achievable is usually taken as an index to maximum cardiovascular function, i.e. it is a good criterion of how well the various physiological functions can adapt to the increased metabolic needs of work or exercise.

The processes of metabolism involved in muscular work are complex, but well detailed in any physiology text e.g. Selkurt (1966) (34), Åstrand and Rodahl (1970) (4), or Watson (1971) (37)

Related work investigating the contribution of aerobic or anaerobic work to maximum oxygen consumption has suggested that the relationship between oxygen intake and work is linear throughout a moderate exercise range, (this being aerobic work); but as exhaustion is reached, anaerobic processes will become more prominent. Clarke and Clarke (1970) (9). Åstrand (1952) (2) supported this by using male and female subjects at a variety of work loads and oxygen intake values. The blood Lactate values that he obtained during exercise served to indicate this reliance upon anaerobic reserves. Hesser (1965) (22) gives evidence that in the steady state, the upper limit for performing work under truly aerobic conditions corresponds to about $70 \%$ of the maximum oxygen consumption.

Therefore, considering this information and the fact that once maximum oxygen consumption is attained, a large oxygen debt has been incurred, it is important to realize that maximum oxygen consumption or uptake is NOT maximum aerobic working capacity.

P. O. Åstrand (1952) (2) and I. Åstrand (1959) (1) used two criteria to evaluate whether or not the subject's maximum level for oxygen uptake had been attained. These were:

(1) that blood lactate concentration is high: $90-100$ $\mathrm{mg} / 100 \mathrm{ml}$ after work of at least 4 minutes duration;

(2) that oxygen uptake does not increase despite a rising work load, but reaches a level.

A great deal of study has also been done to predict maximum aerobic capacity from submaximal loads. Åstrand et al (1954) (3). Because Åstrand found a straight line relationship between heart rate and oxygen consumption through submaximal work loads, he suggested that an individual's maximum oxygen uptake, or capacity to do work could be predicted. His prediction is based on registration of heart rate during steady state and then an extrapolation to a fixed heart rate or to an assumed maximum heart rate. Based on this, Âstrand and Ryhming (1954) (3) developed a nomogram for calculation of aerobic capacity. Although recent adjustments have been made to account for difference between ages and sex, there are still critics of this method of prediction. Rowell, Taylor, Wang (1964) (33), Watson (1970) (36).

Mitchell et al (1958) (30), studying the factors determining maximum oxygen intake concluded that the increase in cardiac output (Q) and the ability of the tissues to extract oxygen from the blood perfusing them 
(that is to increase the arteriovenous oxygen difference (a-v) $\mathrm{O}_{2}$ are the only factors of importance. They believe that the ability of the vascular bed to accommodate the increased cardiac output is of minor importance, and that pulmonary ventilation ( $\left.\hat{V}_{E}\right)$ and gas exchange are never limiting factors.

Cardiac output may be defined as a product of stroke volume and heart rate: $\mathrm{Q}=\mathrm{SV} \times \mathrm{f} H$

Åstrand has suggested that stroke volume increases with work up until approximately $40 \%$ maximum oxygen uptake, and then levels off. Therefore any further increase in cardiac output must be due entirely to heart rate. It has been found by Donald et al (1955) (15) that both heart rate and cardiac output show a linear relationship to work up to approximately $70 \%$ maximum oxygen uptake. But since both of these parameters level off, any further increase in the volume of oxygen consumption $\left(\mathrm{V}_{02}\right)$ must be due to the (a-v02) difference. Selkurt (1966) (34) supports this, stating that the reserve provided by an increase in the oxygen (a-v) $0_{2}$ difference can provide for a 2 to 3 times increase in oxygen utilization by active muscles.

In this present study the mean maximum oxygen uptake values for the male subjects, $(4.181 / \mathrm{min} ., 61.3$ $\mathrm{ml} / \mathrm{min} / \mathrm{kg}$.), was nearly identical to that found by Maksud (1970) (27) with his skaters, and was similar to those values reported by Magel (1967) (26), but slightly lower than those found for endurance athletes by Hermansen and Saltin (1969) (21), their mean being $4.631 / \mathrm{min}$. Values were significantly lower than those found in Swedish runners by Astrand and Saltin (1967) (6), even when body weight was accounted for. Mean $\mathrm{V}_{2}$ was however, significantly higher than those values for middle aged athletes measured by Grimby et al (1966) (16), their measure being $3.51 / \mathrm{min}$; ; or by Pirnay et al (1970) (32), who obtained a $\mathrm{V}_{0_{2}}$ of 3.61 $1 /$ min. during treadmill exercise.

Maximum oxygen uptake values for the female subject (mean $=2.51 \mathrm{1} / \mathrm{min}$.) were slightly lower than those for Maksud's female speed skaters (1970) (27). Group 1 however, achieved a mean $\mathrm{V}_{2}$ maximum of $3.131 / \mathrm{min}$. which was very similar to those of Åstrand and Saltin's (1967) (6), 400-800 meter female runners, and Hermansen's et al (1965) (20), Norwegian female athletes.

The mean maximal heart rates (at maximum $\dot{V}_{02}$ ) for the present study's male and female athletes were lower than those values reported for olympic speed skaters, Maksud (1970) (27), or top athletes, Hermansen (1969) (21). Some of these differences may be attributed to an individual male who reached maximum $\mathrm{V}_{2}$ long before he reached his maximum heart rate, and to an individual female who had a particularly low heart rate of 162 beats/min. at maximum $\mathrm{V}_{02}$. As was expected, these male olympic athletes had significantly lower, and thus more efficient heart rates than those of Magel's college swimmers, (1967) (26).

- Present data supports critics of §̊strand's maximum $\dot{\mathrm{V}}_{02}$ predictions based on submaximal heart rates, Rowell et al (1 964) (33). Maximum heart rates were reached prior to maximum oxygen uptake in $70 \%$ of the subjects tested by the authors. A high oxygen extraction of $5.0 \%$ accounted for R. McA. achieving maximum oxygen consumption at two work loads prior to exhaustion, even though his pulmonary ventilation at the time was only $661 / \mathrm{min}$. This indicated that although this individual has a high capacity for work, he is more efficient at the lower work load of 260 watts. If he was able to maintain this high $\mathrm{FUO}_{2} \%$ to exhaustion, with his present capacity for pulmonary ventilation, (which continued to rise throughout the work period), he could theoretically by extrapolation, increase his maximum oxygen consumption to $4.21 \mathrm{1} / \mathrm{min}$. at 340 watts.

The relationship of heart rate to $\dot{V}_{02}$ is not as clearly indicated by the means of the female subjects. However, the three females who attained maximum $\dot{\mathrm{V}}_{0_{2}}$ prior to reaching maximum heart rates were of the second, lesser trained group. It is possible that the ability to reach maximum heart rate first is a resultant of training, or that these subjects (physical education students) did not push themselves quite as far as the competitive athletes. However, the very high heart rates recorded with these subjects at exhaustion indicated that they did elicit maximum effort. Obviously, their physiological capacity was inferior in comparison to the better trained athletes.

In both groups of subjects, the mean maximum ventilations are relatively low in comparison with related literature: $1051 / \mathrm{min}$., and $701 / \mathrm{min}$. male and female respectively as compared to $127.61 / \mathrm{min}$. and 96.5 $1 / \mathrm{min}$. by Maksud (1970) (27); or $1181 / \mathrm{min}$., and 99 $1 / \mathrm{min}$. by Hermansen and Anderson. Their female students however, only achieved a ventilation of 71 $1 / \mathrm{min}$. This discrepancy could indicate a more efficient oxygen extraction to achieve similar $\mathrm{V}_{0_{2}}$ values. This is the case for the females, as the authors report an oxygen extraction of $3.8 \%$ as compared to Maksud's $3.5 \%$ for his skaters. However, for his male olympic skaters Maksud presents an FU0 $2 \%$ of $4.0 \%$ compared to the authors mean FUO2 of $3.8 \%$. This discrepancy would seem to support Mitchell et al (1958) (30) who believed that pulmonary ventilation and gas exchange are never limiting factors in determining maximum oxygen uptake. This is supported in that $\dot{\mathrm{V}}_{\mathbf{E}}$ continues to increase up to exhaustion. Mitchell suggests instead that cardiac output and arteriovenous oxygen differences are the only important factors. 
The authors maintain that oxygen removal is a major factor, regulating exercise pulmonary ventilation, although increases in carbon dioxide tensions and acidosis, are of equal importance. In any ergometric study pulmonary ventilation must also be affected by the biophysical limitations of the facemask valve system.

Selkurt (1966) (34) stated that control of the cardiovascular system utilizes four primary cardiovascular reserves:

(1) heart rate reserve;

(2) systolic volume reserve;

(3) diastolic reserve volume (the latter being minimal);

(4) venous oxygen reserve (i.e. an increase in (a-v) $0_{2}$ difference).

Both increased heart rate and increased stroke volume, provided primarily by this decrease in systolic volume, contribute to increased cardiac output. For those athletes who are better trained, maximum heart rates are lower than those of untrained subjects for any given work load or value of oxygen consumption, indicating greater stroke volumes. This more efficient ejection with each heart beat is in agreement with literature concerning the increased efficiency of the heart with training.

It has been shown however, that stroke volumes level off at submaximal heart rates, so that any further increase in cardiac output must be a result of increased heart rate. The authors have shown that the heart rate plateaus, but $\dot{V}_{0}$ continues to increase for a short period of time. If $\dot{\mathrm{V}}_{\mathrm{O}_{2}}$ is cardiac output times the arteriovenous oxygen difference, and the cardiac output reaches its maximum, the further increase in $\mathrm{V}_{0_{2}}$ is a result of increased oxygen utilization by the active muscles, provided by an increase in the (a-v) $0_{2}$ difference.

When the heart rate responses of the males and females are compared at the same work load, the results show that the females have higher heart rates. Although cardiac output was not measured, the authors think it is reasonable to assume that the product of heart rate and stroke volume would be significantly smaller for the females. Therefore, as maximum $\mathrm{V}_{\mathrm{O}_{2}}$ is approached, increases in $\dot{\mathrm{V}}_{2}$ of the female is achieved more by increases in heart rate, and perhaps a higher (a-v) $0_{2}$ difference. The higher female heart rate could also compensate for a lower stroke volume

Exactly what limits oxygen uptake remains obscure. Because $\mathrm{V}_{2}$ levels off during the last stages of maximal exertion, it appears that a comfortable steady state has been achieved, i.e. the oxygen being delivered to the tissues is equal to the tissue demand. Individual muscle fibres lose tension as they tire and more fibres must be brought into use, the oxygen demand is too great even to be alleviated by the increasing pulmonary ventilation. The percentage of oxygen being extracted for all subjects tested, decreased from a maximum value obtained prior to maximum $\mathrm{V}_{0_{2}}$. With increasingly less oxygen reaching the tissues, there seems to be a point at which aerobic mechanisms can no longer accommodate the oxygen requirements of the working muscles. Thus anaerobic reserves are utilized. Because a human can work under totally anaerobic conditions for a restricted period of time, total exhaustion occurs and a sizeable oxygen debt has resulted.

It is difficult to determine with the present data exactly when these anaerobic mechanisms come into play, as blood lactate levels were not measured. Certainly however, it seems that maximum work capacity and maximum oxygen consumption are not merely aerobic work capacity, but include anaerobic stores. The relationship between $\dot{\mathrm{V}}_{2}$ and $\mathrm{V}_{\mathrm{E}}$ (Figures 1 and 2) showed that at low levels of work pulmonary ventilation increased linearly to the increase in oxygen uptake, but out of linearity during heavy exercise. This curvilinear exercise induced hyperventilation was probably due to the occurrence of anaerobic products from the muscle metabolism, in the venous blood. The acidosis produced from these anaerobic products would cause a decrease in bicarbonate concentration, producing a respiratory compensation, in an attempt to eliminate the excess carbon dioxide produced. Excess carbon dioxide in the expired air due to the buffering of lactic acid, would also increase the gas exchange ratio, causing a ventilatory compensation to maintain blood $\mathrm{pH}$ at a normal level. The females in this investigation showed a more pronounced hyperventilation curve than the males, indicating that the range of anaerobic participation of energy release is reached at a lower work load, with females.

In summary, if maximum $\dot{V}_{02}$ is to be considered the primary physiological variable which best defines efficiency or capacity of the cardiovascular or respiratory systems, much more time and study will have to be devoted to realizing its true and complete physiological meaning, and those factors which limit it.

Within the present study, the authors have merely measured maximum oxygen consumption for male and female athletes during strenuous exercise on the bicycle ergometer, and sought to establish some relationships between maximum $\hat{V}_{0_{2}}$, heart rate, pulmonary ventilation, the percentage of oxygen extraction and the capacity to do prolonged work.

The authors have reported relatively low pulmonary 
ventilation values. These do not however, necessarily indicate an inability to ventilate the lungs. It may in fact, as Watson (1970) (36) suggested, represent a higher diffusion rate of oxygen from alveolar air to arterial blood,.i.e. greater efficiency, or be caused by limitations of the use of a facemask valve system. Although maximum oxygen consumption is dependent upon maximum ventilation, it is not limited by this parameter. The assessment of anaerobic energy release during work may be detected with the exercise induced hyperventilatory respiratory response, and the authors maintain that anaerobiosis at work, differs in males and females, and that stronger participation of anaerobiosis attributes to the lower aerobic capacities of the female athletes.

Whereas maximum $\dot{\mathrm{V}}_{\mathrm{O}_{2}}$ values are achieved as a result of increased oxygen utilization by the active muscles, provided by an increase in the (a-v) $0_{2}$ difference, this parameter may also be the limiting factor. More specifically, it may be the tissue's ability to extract the oxygen from the blood. If the athletes could maintain the maximum percentage of extraction of oxygen, achieved approximately mid-way through the work period, through to exhaustion, much higher values for oxygen consumption would theoretically be achieved.

Once maximum $\dot{V}_{0_{2}}$ is achieved anaerobic mechanisms supplement aerobic capacity for a very limited amount of further work.
It seems evident that the great circulatory capacity for oxygen transport and diffusion that these subjects do possess, is a result of both natural endowment and intensive training. While it remains difficult to determine exactly how much each contributes, it is important for the athletics coach to realize the many varied physiological functions that must be considered in any training programme.Ideally, each athlete could be tested, and his individual needs defined, and a training programme set.

It would be interesting to correlate the data from investigations such as these to actual track or athletic performances in something more than subjective comparisons. Are the roles in which the various parameters interplay different for those athletes who depend more on anaerobic mechanisms rather than aerobic mechanisms, (sprinters vs. distance runners)? How much of a race is skill, strategy and motivation and how much actually physiologically dependent? How much of that physiological dependency is natural endowment and what is trainable? Interesting questions that need to be answered.

\section{Acknowledgements}

The authors wish to express their gratitude to Prof. W. F. Floyd and Dr. E. J. Hamley of the Ergonomics Dept., Loughborough Un iversity; to Miss A. J. Bambra and the Staff of Chelsea College of Physical Education, and to the athletes and students who acted so patiently as subjects for this investigation.

\section{REFERENCES}

1. $\AA$ ASTRAND, IRMA, ÅSTRAND, PER-OLAF, and RODAHL, K., 1959. "Maximal heart rate during work in older men." J. Appl. Physiol. 14:562-566.

2. ÅTRAND, P.-O., 1952. "Experimental studies of physical working capacity in relation to sex and age." Munksgaard, Copenhagen. Chap. 3,9.

3. ÅSTRAND, P.-O., and RYHMING, I., 1954. “A nomogram for calculation of aerobic capacity (physical fitness) from pulse rate during submaximal work." J. Appl. Physiol. 7:218-221.

4. ÅSTRAND, P.-O., and RODAHL, K., 1970. Textbook of Work Physiology. New York and London, McGraw Hill Book Co.

5. ÅSTRAND, P.-O., and SALTIN, B., 1961. "Maximum oxygen uptake and heart rate in various types of muscular activity." J. Appl. Physiol. 16:977-981.

6. ÅSTRAND, P.-O., and SALTIN, B., 1967. “Maximum oxygen uptake in athletes.” J. Appl. Physiol. 23:353-358.

7. ÅSTRAND, P.-O., and SALTIN, B., CUDDY, T. E., and STENBURG, J., 1964. “Cardiac output during submaximum and maximum work." J. Appl. Physiol. 19:268-273.

8. CARTER, J. S. L., KOSCH, F. W., BOYER, J. L., PHILLIPS, W. H., ROSS, W. D. and SUCEC, A., 1966. "Abstract-Structural and Functional Assessments of a Champion Runner - Peter Snell." Physical Education Research Laboratory, San Diego State College, Calif. 
9. ClaRKE, H. H., and CLARKE, D. H., 1970. Research Processes in Physical Education, Recreation and Health. New Jersey, Prentice Hall, Inc.

10. COTES, J., DAVIES, C. T. M., HEALY, M. J. R., 1967. "Factors relating to maximum oxygen uptake in young male and female subjects." J. Physiol. 189, 79p.

11. deVRIES, H., 1967. Physiology of Exercise. Duburque, Iowa, Wm. C. Brown Co. Inc. p155.

12. DILL, D. B., 1933. "Fatigue and work efficiency.” Personnel, 9:112-113.

13. DILL, D. B., EDWARDS, H. T., and MARGARIA, R., 1933. "Possible Mechanisms of contracting and paying the oxygen debt, and the role of lactic acid in muscular contraction." American Heart Journal. 106:689-715.

14. DILL, D. B., EDWARDS, H. T., and TALBOTT, J. H., 1932. "Studies in muscular activity." J. Physiol. 77:49-62.

15. DONALD, K. N., BISHOP, J. M., CUMMING, G., and WADE, O. L., 1955. "The effects of exercise on the cardiac output and circulatory dynamics of normal subjects." Clinical Science, 14:37-75.

16. GRIMBY, G., NILSSON, J. N., and SALTIN, B., 1966. "Cardiac output during submaximal and maximal exercise in active middle-aged athletes." J. Appl. Physiol. $21: 1150-1156$.

17. HAMLEY, E. J., and SEN, R. W., 1968. "Physiological evaluation of tolerance to heavy work." International Colloquium on Muscular Exercise and Training, Darmstact.

18. HENRY, F. M., 1951. "Aerobic oxygen consumption and alactic debt in muscular work." J. Appl. Physiol., 3:427-438.

19. HERBST, R., 1928. Dtsch. Arch. Klin. Med., 162:33-55.

20. HERMANSEN, L., and ANDERSON, K. L., 1965. "Aerobic work capacity in Norwegian men and women." J. Appl. Physiol., 20:425431.

21. HERMANSEN, L., and SALTIN, B., 1969. “Oxygen uptake during maximal treadmill and bicycle exercise.” J. Appl. Physiol., 26:31-37.

22. HESSER, C. M., 1965. "Énergy cost of alternating positive and negative work." Acta Physiologica Scandanavica, 63:84-93.

23. HILL, A. V.,1926. Muscular Activity. Baltimore, Maryland, The Williams and Wilkland Co.

24. HILL, A. V., and LUPTON, H., 1923. "Muscular exercise, lactic acid and the supply and utilisation of oxygen." Quarterly Journal of Medicine, 16:155-171.

25. IKAI, M., 1966. “Work capacity of the Japenese related to age and sex.” J. S. Med. Phys..Fitness, 6:100-105.

26. MAGEL, J. R., and FAULKNER, J. A., 1967. "Maximum oxygen uptakes of college swimmers." J. Appl. Physiol., 22:929-935.

27. MAKSUD, M. G., WILEY, R. L., HAMILTON, L. H. and LOCKHART, B., 1970. "Maximal Vo2, ventilation and heart rate of olympic speed skating candidates." J. Appl. Physiol. 29:186-189.

28. MATSUI, H., and MIYASHITA, M., 1971. “Aerobic work capacity of Japenese adolescents." J. S. Med. Phys. Fitness, 11.

29. MICHAEL, E. D., HORVATH, S. M., 1965. "Physical work capacity of college women." J. Appl. Physiol., 20:263-266. 
30. MITCHELL, J. H., SPROULE, B. J., and CHAPMAN, C. B., 1958. "The physiological meaning of the maximal oxygen intake test." J. Clinical Invest., 37:538-547.

31. MOREHOUSE, L. E., and MILLER, A. T., 1967. Physiology of Exercise. Tondon and St. Louis, the C. V. Mosby Co.

32. PIRNAY, F., DEROANNE, R., PETIT, J. M., 1970. "Maximal oxygen consumption in a hot environment." J. Appl. Physiol., 28:642-645.

33. ROWELL, L. B., TAYLOR, H. L., and WANG, Y., 1964. "Limitations to prediction of maximal oxygen intake." J. Appl. Physiol., 19:919-927.

34. SELKURT, E. E. (ed.), 1966. Physiology. Boston, Mass., Little, Brown and Co.

35. TAYLOR, H. L., BUSKIRK, E., and HENSCHEL, A., 1955. "Maximal oxygen intake as an objective measure of cardio-respiratory performance." J. Appl. Physiol., 8:73-80.

36. WATSON, R., 1970. "Aerobic work capacity of the female physical education student." Lung Function and Work Capacity. Univ. of Salford, British Association of Sports Medicine.

37. WATSON, R., 1971. "Chemistry of Muscular Contraction" Athletics Coach. 5:18-21.

38. WILMORE, J. H., 1969. "Maximum oxygen intake and its relationship to endurance capacity on a bicycle ergometer.” Research Quarterly, 40:203-210. 